\title{
Functional interactions between a glutamine synthetase promoter and MYB proteins
}

\author{
Josefa Gómez-Maldonado ${ }^{1}$, Concepción Avila ${ }^{1}$, Fernando de la Torre ${ }^{1}$, Rafael Cañas ${ }^{1}$, Francisco M. Cánovas ${ }^{1}$ and \\ Malcolm M. Campbell ${ }^{2 *}$ \\ ${ }^{1}$ Biología Molecular y Bioquímica, Instituto Andaluz de Biotencología, Unidad Asociada UMA-CSIC, Universidad de Málaga, \\ Campus Universitairo de Teatinos, E-29071 Málaga, Spain, and \\ ${ }^{2}$ Department of Plant Sciences, University of Oxford, South Parks Road, Oxford OX1 3RB, UK
}

Received 5 May 2004; revised 11 May 2004; accepted 30 May 2004.

*For correspondence (fax +44 1865 274074; e-mail malcolm.campbell@plants.ox.ac.uk).

\begin{abstract}
Summary
In Scots pine (Pinus sylvestris), ammonium assimilation is catalysed by glutamine synthetase (GS) [EC 6.3.1.2], which is encoded by two genes, PsGS1a and PsGS1b. PsGS1b is expressed in the vascular tissue throughout the plant body, where it is believed to play a role in recycling ammonium released by various facets of metabolism. The mechanisms that may underpin the transcriptional regulation of PsGS1b were explored. The $P s G S 1 b$ promoter contains a region that is enriched in previously characterized cis-acting elements, known as $A C$ elements. Pine nuclear proteins bound these AC element-rich regions in a tissue-specific manner. As previous experiments had shown that R2R3-MYB transcription factors could interact with AC elements, the capacity of the AC elements in the PsGS1b promoter to interact with MYB proteins was examined. Two MYB proteins from loblolly pine (Pinus taeda), PtMYB1 and PtMYB4, bound to the PsGS1b promoter were able to activate transcription from this promoter in yeast, arabidopsis and pine cells. Immunolocalization experiments revealed that the two MYB proteins were most abundant in cells previously shown to accumulate PsGS1b transcripts. Immunoprecipitation analysis and supershift electrophoretic mobility shift assays implicated these same two proteins in the formation of complexes between pine nuclear extracts and the PsGS1b promoter. Given that these MYB proteins were previously shown to have the capacity to activate gene expression related to lignin biosynthesis, we hypothesize that they may function to co-regulate lignification, a process that places significant demands on nitrogen recycling, and GS, the major enzyme involved in the nitrogen recycling pathway.
\end{abstract}

Keywords: MYB, glutamine synthetase, transcription, lignin, nitrogen.

Introduction

The efficient acquisition and allocation of nitrogen is a crucial component of plant growth and development. Plants require mechanisms both to assimilate nitrate-derived ammonium and to reintegrate liberated ammonium back into metabolism. The enzyme glutamine synthetase (GS) fulfils both of these roles.

Glutamine synthetase [EC 6.3.1.2] catalyses the ATPdependent condensation of ammonium and glutamate to form glutamine (Cánovas et al., 1998). In angiosperms, this reaction is catalysed by two different GS isoforms, GS1 and GS2. GS1 functions in the cytoplasm, whereas GS2 is localized to the chloroplast (Bielawski, 1994; Chen and Silflow, 1996; Cren and Hirel, 1999; Edwards et al., 1990;
Hirel et al., 1984; McNally et al., 1983; Suárez et al., 2002; Tingey et al., 1988; Tobin and Yamaya, 2001). In contrast to angiosperms, most gymnosperms appear to possess only the cytosolic form of GS, GS1 (Cánovas et al., 1998; Suárez et al., 2002). In Pinus sylvestris, two different genes encode GS1, PsGS1a and PsGS1b (Avila et al., 1998; Avila Sáez et al., 2000; de la Torre et al., 2002). PsGS1a and PsGS1b have overlapping yet distinct patterns of expression. PsGS1a is expressed almost exclusively in the chlorophyllous parenchyma of photosynthetic tissues, whereas $P s G S 1 b$ is expressed primarily in vascular cells throughout the plant (Avila et al., 2001). PsGS1a is hypothesized to function in a manner similar to chloroplast-localized 
angiosperm GS2, assimilating nitrogen released in photosynthetic metabolism (Avila et al., 2001). In contrast, PsGS1b is proposed to play an important role in nitrogen transport and other metabolic functions associated with vascular development.

One of the most important roles for PsGS1b in vascular tissues is to meet the nitrogen recycling needs during lignin synthesis in xylem cells. Lignins are complex polymers that are embedded in the cell walls of specialized plant cells such as xylem (Campbell and Sederoff, 1996). Lignins are derived from the amino acid phenylalanine; consequently, in cells actively synthesizing lignins, there is a significant demand for nitrogen for phenylalanine biosynthesis. During lignin biosynthesis, there is also a significant release of organic nitrogen in the form of ammonium, which occurs when phenylalanine is deaminated to channel it into lignin biosynthesis. This scenario would result in severe nitrogen deficiency if lignifying cells did not possess an efficient nitrogen recycling mechanism. It has been proposed that GS, such as PsGS1b, plays a key role in recovering and re-assimilating the nitrogen released in cells that are actively engaged in phenylpropanoid metabolism, such as lignifying cells (van Heerden et al., 1996; Razal et al., 1996; Singh et al., 1998).

One way to ensure efficient nitrogen recycling in lignifying cells would be to couple nitrogen recycling and lignification in both time and space. This can be accomplished by transcriptional regulation. The coordinate regulation of nitrogen recycling and lignin biosynthesis can be brought about by transcription factors that simultaneously regulate the genes encoding rate-limiting steps in lignin biosynthesis, as well as those involved in nitrogen recovery, such as PsGS1b.

There is growing evidence that several of the genes encoding the enzymes of the lignin biosynthetic pathway are co-ordinately regulated at the transcriptional level (Anterola et al., 2002; Hawkins et al., 2003). Functionally defined, conserved, cis-acting motifs were found in the promoters of many genes encoding lignin biosynthetic enzymes (Bell-Lelong et al., 1997; Capellades et al., 1996; Hatton et al., 1995; Hauffe et al., 1993; Lacombe et al., 2000; Leyva et al., 1992; Nair et al., 2002; Raes et al., 2003). These motifs are thought to play a role in specifying the spatial and temporal expression of the lignin biosynthetic pathway. The most extensively characterized of these motifs are rich in adenosine and cytosine residues and have been variably referred to as $A C$ elements, $H$ boxes, and PAL boxes. Three different $A C$ elements have been described, AC-I, AC-II and AC-III, which have the sequences ACCTACC, ACCAACC and ACCTAAC, respectively (Hatton et al., 1995). These cis-acting elements are likely to function as the target for transcription factors whose role is to control the expression of genes encoding lignin biosynthetic enzymes.
Members of the R2R3-MYB family of transcription factors may regulate lignification through their interaction with $A C$ elements. Recently, two members of the Pinus taeda R2R3MYB family that are expressed in lignifying cells were shown to bind to and activate transcription from AC elements, and that, in plant cells, they could regulate gene expression related to lignin biosynthesis (Patzlaff et al., 2003a,b). These data suggest that these two proteins, PtMYB1 and PtMYB4, might function to regulate lignin biosynthesis in lignifying tissues. It is also possible that PtMYB1 and PtMYB4 function in the coordinate regulation of lignin biosynthesis with other genes that contain cis-acting $\mathrm{AC}$ elements.

The experiments described in this paper begin to test the hypothesis that two pine MYB proteins, PtMYB1 and PtMYB4, might function as coordinate regulators of not only lignification, but also nitrogen recycling associated with this process, as both carbon and nitrogen metabolism must be co-ordinately regulated during xylem development. To this end, we explored the possibility that pine MYB1 or pine MYB4 might form part of a regulatory mechanism that directs the vascular-localized expression of the pine GS gene, GS1b. The mechanisms underpinning this pattern of expression are unknown, but may be due, at least in part, to cis-acting elements within the promoter of the PsGS1b gene. We show that the PSGS1b promoter possesses a region with an abundance of $A C$ elements. Given that these elements can function as targets for the regulation of gene expression by members of the R2R3-MYB family of transcription factors, we tested the hypothesis that two pine MYBs, which are expressed in vascular tissue, might be able to both bind, and activate transcription from, the PsGS1b promoter.

\section{Results}

$A C$ elements are present in the PsGS1b minimal promoter

Sequence analysis of the $403 \mathrm{bp}$ of sequence immediately upstream of the transcriptional start site in the PsGS1b promoter identified a region that had a concentration of $A C$ elements, referred to as GS1b AC (Figure 1a) (GómezMaldonado et al., 2004). Within this region, three subregions were identified that had at least one adenosine- and cytosine-rich motif that might function as a putative R2R3MYB binding site. The regions containing these $A C$ elements were referred to as GS1b AC box 1, GS1b AC box 2, GS $1 b$ AC box 3 , where box 1 is proximal to the transcriptional start site, and box 3 is the most distal (Figure 1a).

GS1b AC box 1 contains three putative AC elements (Figure 1b). The first of these elements is identical to AC-I, except for a $C$ to $A$ substitution at the $3^{\prime}$ end of the motif. The second two AC elements in GS1b AC box 1 overlap. An AC-II element with an $A$ to $T$ substitution at the 5 end overlaps with another $A C$-II element that contains an $A$ to $C$ substitution at position 5 in the motif. GS1b AC box 2 contains one 
(a) GS1b Promoter

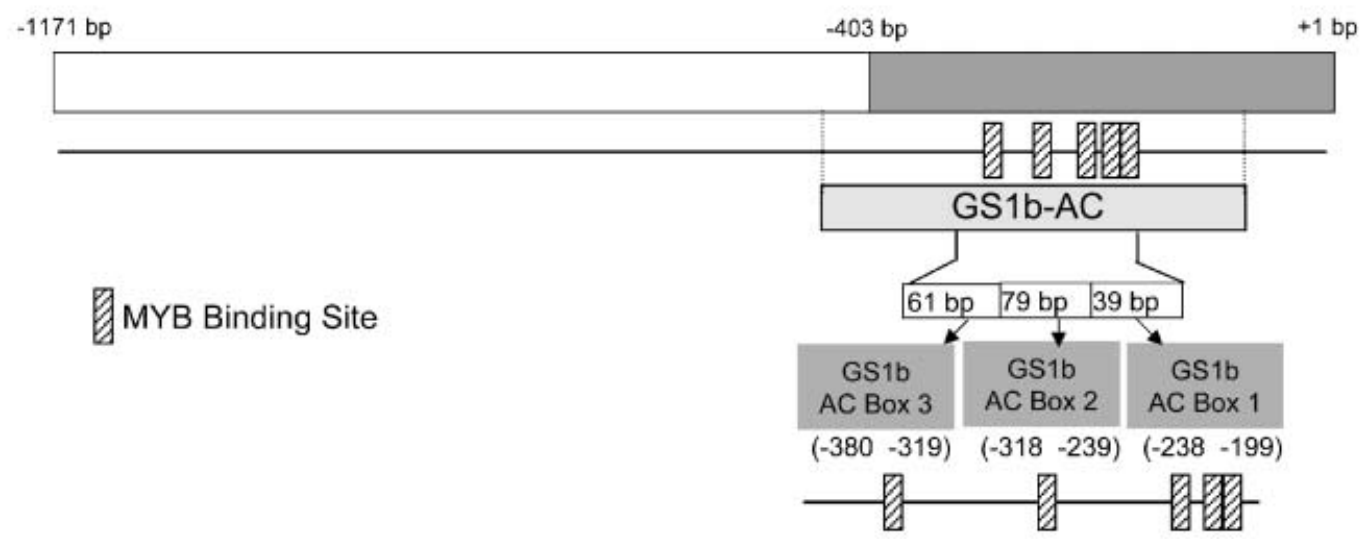

(b) GS1b AC box 1

\begin{tabular}{|c|c|c|c|c|}
\hline & AC-I & & $A C-\|C A-\|$ & \\
\hline $5^{\prime}$ AAAATATTG & ACCTACA & AACCACCGCAG & वACCC & $\mathrm{T}$ \\
\hline $3^{\prime}$ TTTTATAAC & TGGATGT & TTGGTGGCG & AGG & \\
\hline
\end{tabular}

\section{GS1b AC box 2}

$A C-1$

5 'AGTGACTTGAGTCTTCAAGTATAATTACG ACCTATC TAAATCCAATCCCTACCCTACTACATGCGTTTTCACCGGGTA 3.

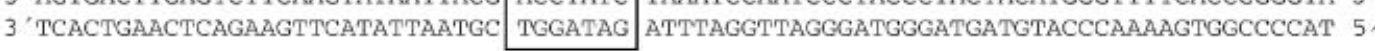

\section{GS1b AC box 3}

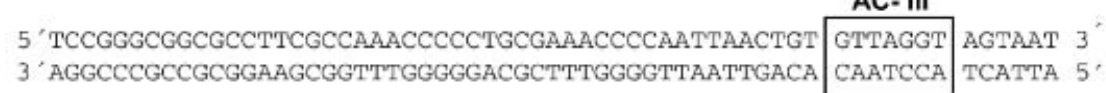

Figure 1. AC element-rich regions of the PSGS1b promoter.

(a) Schematic representation of the GS1b promoter. The position of the transcriptional start site is indicated as +1 . The number indicates the relative distance to -1 . The position of the putative MYB regulation boxes is indicated as striped rectangles. The position and the length (in base pairs) of the GS1b AC boxes is also shown with the putative MYB binding sites that they contain. The diagram is not drawn to scale.

(b) The sequences of GS1b AC boxes 1,2 and 3 are presented. The putative AC elements are within the boxes, and are designated according to the AC element that they most closely resemble. A detailed description is provided in the text.

putative $\mathrm{AC}$ element, which is closest in sequence to $\mathrm{AC}-\mathrm{I}$ but contains a $C$ to $T$ substitution at position 6 in the motif (Figure 1b). GS1b AC box 3 contains one putative $A C$ element, in the antisense orientation, which is closest in sequence to $A C$-III (Figure $1 \mathrm{~b}$ ).

Proteins from pine nuclear extracts bind to PsGS1b boxes containing $A C$ elements

Analysis of protein-DNA interactions by electrophoretic mobility shift assays (EMSAs) indicated that nuclear proteins isolated from pine cotyledons or hypocotyls were able to bind to GS1b AC boxes. There were noticeable differences in the intensity of shifts between the two nuclear extracts. No detectable shift in the mobility of the GS1b AC box 1 was observed when cotyledon nuclear extracts were used, whereas clearly visible mobility shifts were observed when nuclear extracts from pine hypocotyls were used (Figure 2a). This is in contrast to the EMSAs for GS1b AC box 2, where cotyledon nuclear extracts induced much stronger shifts than hypocotyl extracts (Figure 2b), and for GS1b AC box 3, where the shifts induced by hypocotyl nuclear extracts were very weak relative to those generated with cotyledon nuclear extracts (Figure 2c). Binding appeared to be specific and protein dependent, as revealed by competition experiments and treatment of the nuclear extracts with proteinase $\mathrm{K}$.

\section{Recombinant pine MYB proteins bind to PsGS1b AC boxes containing $A C$ elements}

EMSA analysis of the binding of recombinant PtMYB1 and PtMYB4 to the entire PsGS1b AC region revealed that both proteins were able to bind to this target at least once 
(a)
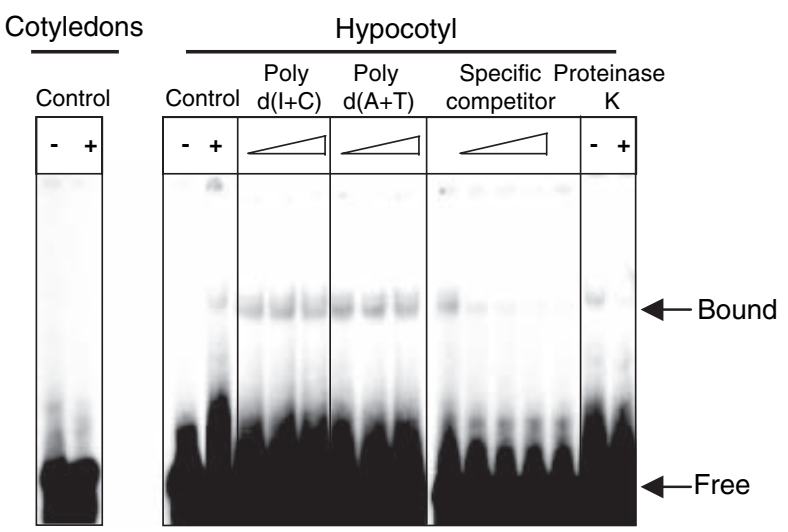

(b)

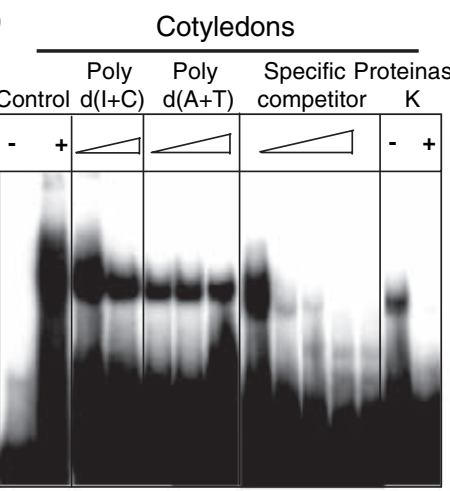

(c)

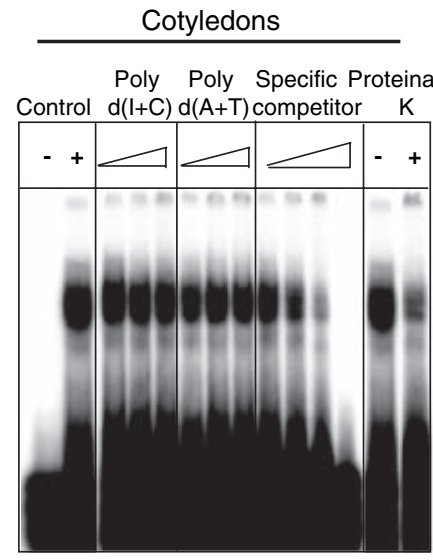

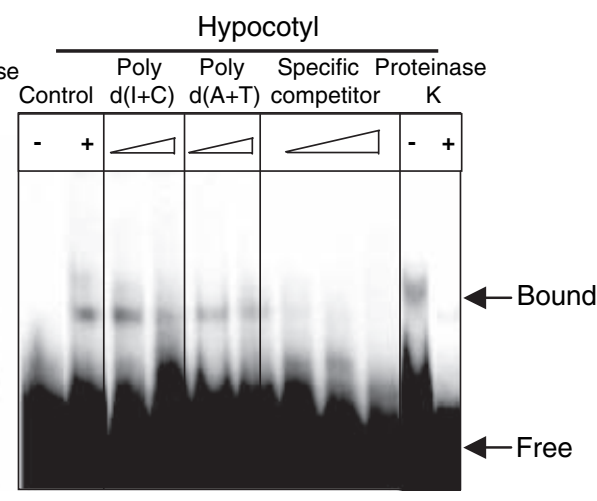

Hypocotyl

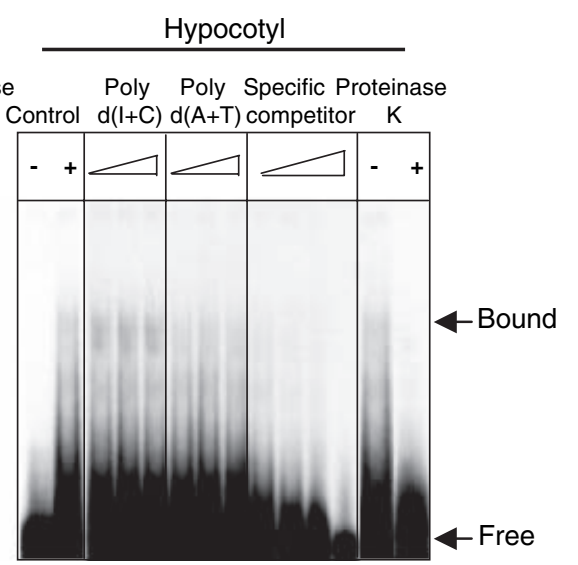

Figure 2. Electrophoretic mobility shift assays showing binding of pine nuclear proteins to GS1b AC boxes.

Protein binding to DNA targets, GS $1 b$ AC box 1 (a), box 2 (b), or box 3 (c), was analysed by electrophoretic mobility shift assays. The amount of protein added in each reactions was 10 and $5 \mu \mathrm{g}$ of nuclear proteins from cotyledons and hypocotyls, respectively. Unspecific competitor (poly $\mathrm{dl}+\mathrm{dC}$ and poly $\mathrm{dA}+\mathrm{dT}$ ) and the specific competitors (cold GS1b AC boxes) were included in the range concentrations indicated in the Experimental procedures. Increasing concentrations of competitor are indicated by the triangle. For the proteinase $\mathrm{K}$ experiment $-1+$ signs indicate with/without proteinase K. The probe without added proteins is designated control $(-)$ and the control $(+)$ is the standard reaction with proteins and without any competitor added.
(Figure 3a). EMSA analysis using individual PsGS1b AC boxes (Figure $3 b$ ) showed that PtMYB1 was able to induce visible mobility shifts when box 1 and box 2 were used as the targets, whereas PtMYB4 was only able to induce a visible shift with box 1 . Neither protein was able to generate a visible mobility shift with box 3 . On the basis of the number of bands that were observed for any given shift, it would appear that there are two PtMYB1 and PtMYB4 binding sites in box 1 as doublet bands were observed. The single bands observed in the shifts involving box 2 suggest that there is only one binding site for the proteins in this target. EMSA competition experiments revealed that $A C$ elements could effectively compete with the PsGS1b AC boxes for MYB binding (Figure 4).

Results with other plant R2R3-MYB proteins indicated that these proteins could induce distortions, including DNA bending, at target-binding sites (Solano et al., 1995). In order to determine whether conformational changes occurred when PtMYB1 or PtMYB4 bound to PsGS1b AC box 1 and box 2, EMSAs were conducted in the presence of divalent cations, which uncover such distortions (Figure 5). DNA bending is revealed by a retardation of the shifted band in the presence of increasing concentrations of divalent cations. Both $\mathrm{Mg}^{2+}$ and $\mathrm{Ba}^{2+}$ enhanced the retardation of the 
Figure 3. Electrophoretic mobility shift assays showing binding of purified, recombinant PtMYB1 or PtMYB4 to regions of the PsGS1 promoter.

Binding of MYB proteins to $G S 1 b A C$ (a) or to the GS1b AC boxes or to an AC-II positive control (b) (see Figure 1a) are shown; $0.6 \mu \mathrm{g}$ of purified, recombinant MYB protein was used in all reactions. The negative control $(-)$ contained no protein. Protein-DNA complexes are designated as 'bound' and the probe alone as 'free'. (a)

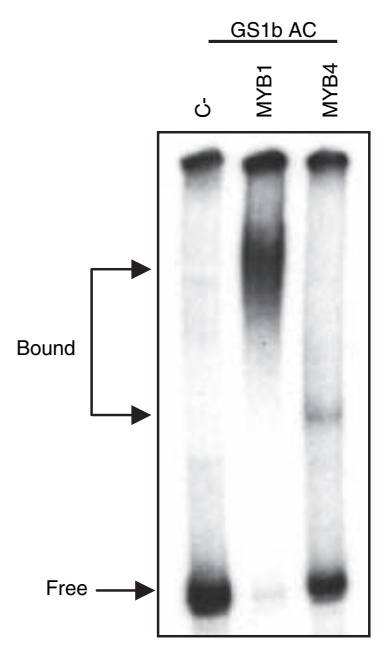

(b)

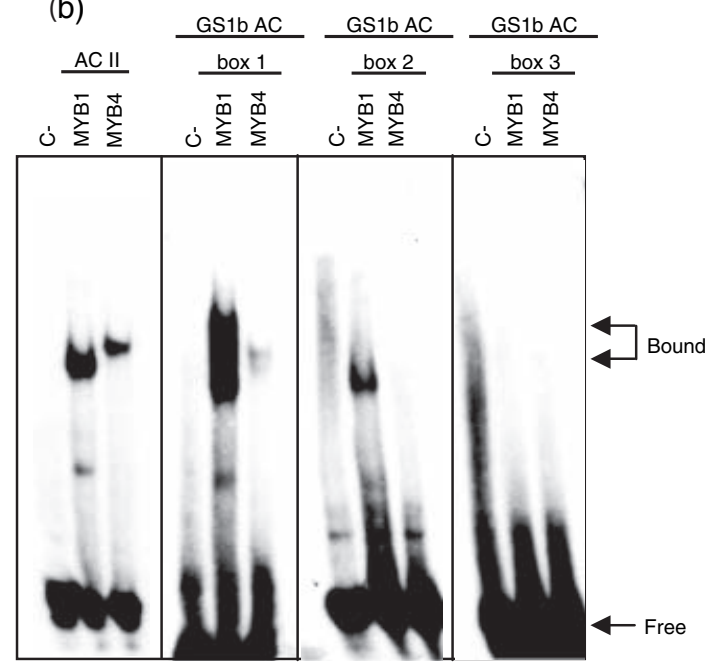

shifted bands through the gel in a concentration-dependent fashion when PtMYB1 was bound to PSGS1b AC box 1. Only $\mathrm{Ba}^{2+}$ enhanced the retardation of PSGS1b AC box 2 . Enhanced shifts by PtMYB1 were not observed when the monovalent cation $\mathrm{Na}^{+}$was used in the shift. Neither were enhanced shifts observed in the EMSAs involving PtMYB4 and PsGS1b AC box 1. These results suggest that PtMYB1, but not PtMYB4, is able to induce conformation changes at sites to which it has bound.
Pine MYB proteins are able to activate transcription from the $A C$ element-containing region of the PsGS1b promoter in yeast

The ability of the PtMYB proteins to activate transcription from the PsGS1b promoter was investigated by transcriptional activation assays using Saccharomyces cerevisiae (Figure 6). A reporter construct was generated which fused the $\mathrm{AC}$ element-containing region of the PSGS1b promoter
Figure 4. Analysis of PtMYB1 or PtMYB4 binding to regions of the PsGS1 promoter.

(a) The sequence of the oligonucleotides $\mathrm{ACl}$, II and II used as specific competitors for the electrophoretic mobility shift assay (EMSA).

(b) EMSAs showing binding of purified, recombinant PtMYB1 or PtMYB4 to regions of the PSGS1 promoter in competition experiment. The free probe without added proteins is designated as control (-). The amount of specific competitors (unlabelled AC elements) is indicated in micrograms. (a)

ACI 5' ACATTGGGCGAGAAAAGCTGATCCCCACCTACCCGGGCTATCTCCCCCTCCTCCTCCGATCTG 3' ACII 5' ACATTGGGCGAGAAAAGCTGATCCCCACCAACCCGGGCTATCTCCCCCTCCTCCTCCGATCTG $3^{\prime}$ ACIII 5' ACATTGGGCGAGAAAAGCTGATCCCCACCTAACCGGGCTATCTCCCCCTCCTCCTCCGATCTG 3'

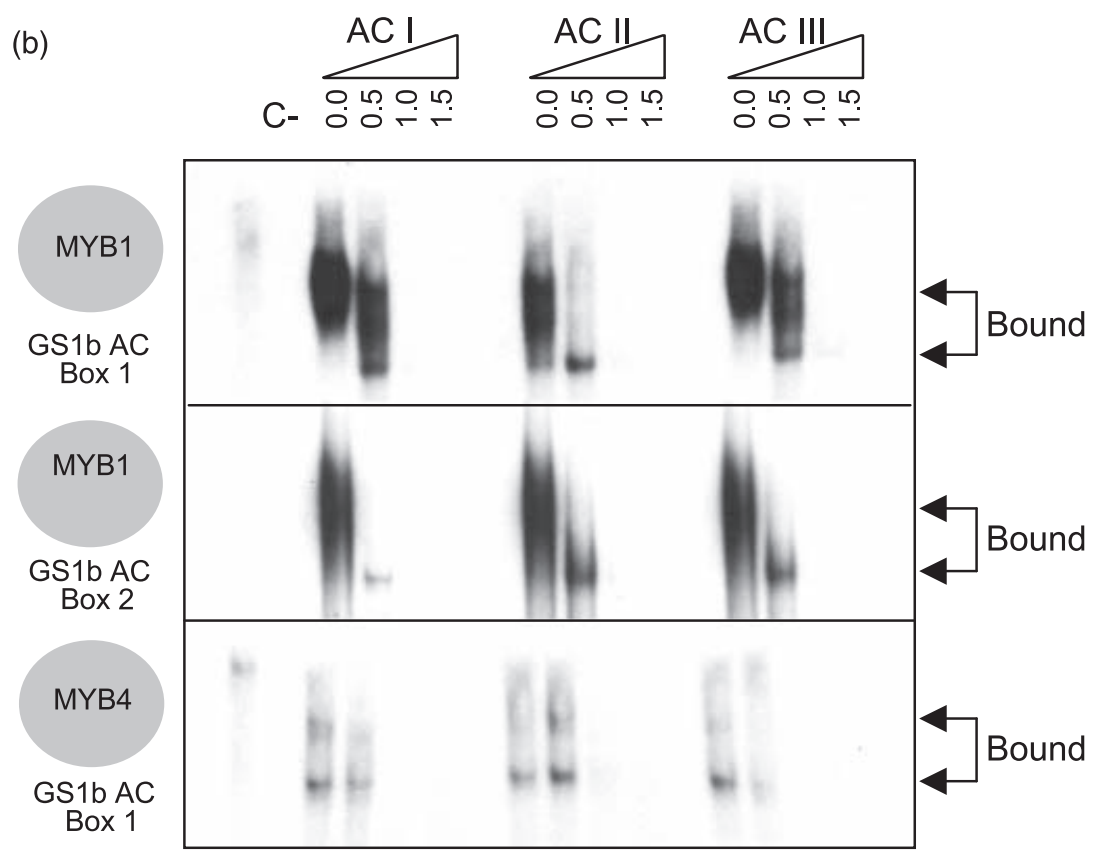




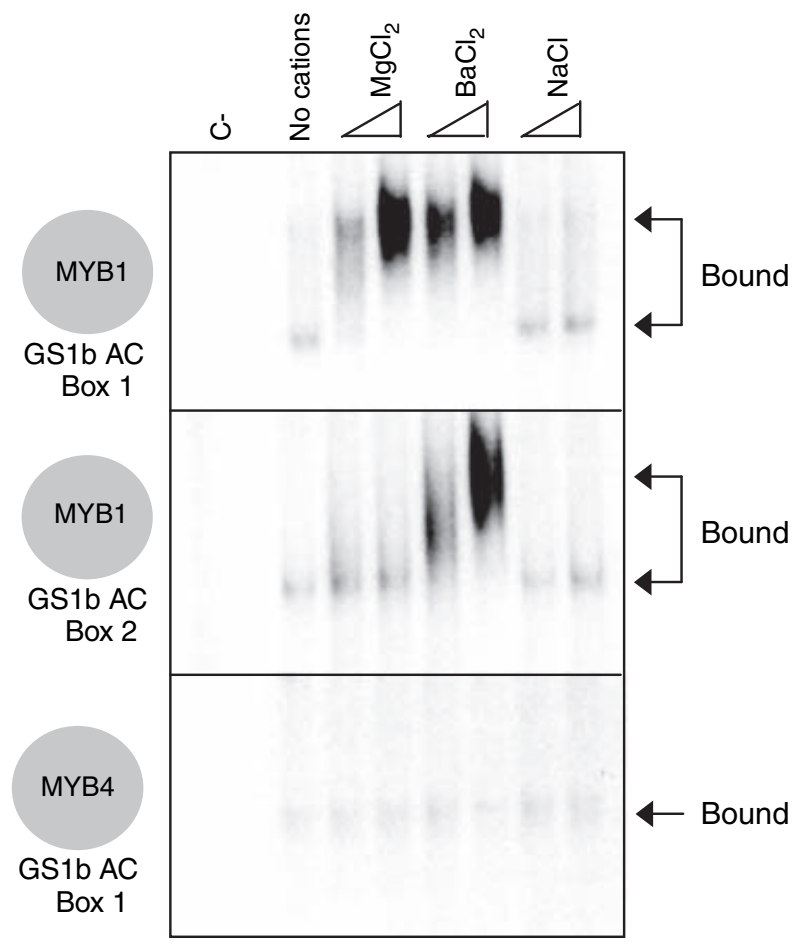

Figure 5. Bending of GS1b AC box sequences by PtMYB1 or PtMYB4 proteins as determined by cation binding in electrophoretic mobility shift assays.

The chloride salt of the cations $\mathrm{Ba}^{2+}, \mathrm{Mg}^{2+} \mathrm{Na}^{+}$was added at two different concentrations, 50 and $100 \mathrm{~mm}$, respectively. The probe without added proteins is designated controls (-). AC-GS1b box 1 was analysed with both MYB proteins but AC-GS1b box 2 only with PtMYB1.

( $G S 1 b A C$ ) to lacZ, so as to drive the expression of $\beta$-galactosidase in a GS1b promoter-dependent fashion (Figure 6a). The MYB coding sequences were introduced into a separate yeast expression vector, which would drive the expression of the MYB proteins only in the presence of galactose as a carbon source. Filter-lift assays of yeast strains containing both vectors showed that both PtMYB1 and PtMYB4 induced expression of $\beta$-galactosidase from the $A C$ element region of the PsGS1b promoter (Figure 6b). Quantitative assessment of PtMYB enhancement of PsGS1b promoter-driven expression was carried out by measuring $\beta$-galactosidase extracted from liquid cultures that had been grown in the presence or absence of galactose. Induction of MYB expression with galactose resulted in a significant increase in $\beta$-galactosidase expression driven from GS1b $A C$, relative to non-induced glucose controls (Figure 6c). Increases in $\beta$ galactosidase expression were observed only in yeast strains that harboured both a construct for MYB expression and the construct that contained fusion between GS1b $A C$ and lacZ (Figure 6c), but not any other combination of vectors (data not shown). The induction of both PtMYB1 and PtMYB4 led to equivalent increases in GS1b $A C$-driven $\beta$-galactosidase expression. (a)

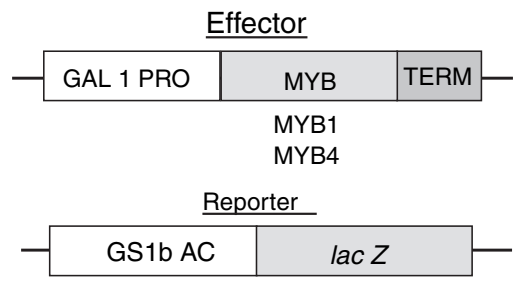

(b)

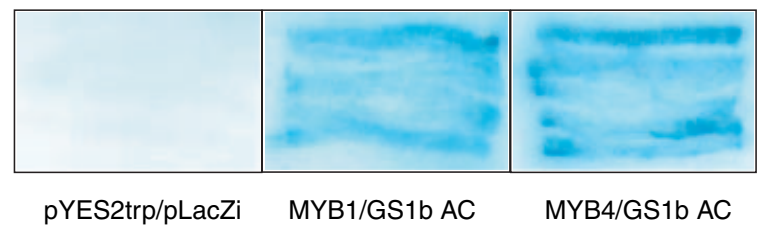

(c)

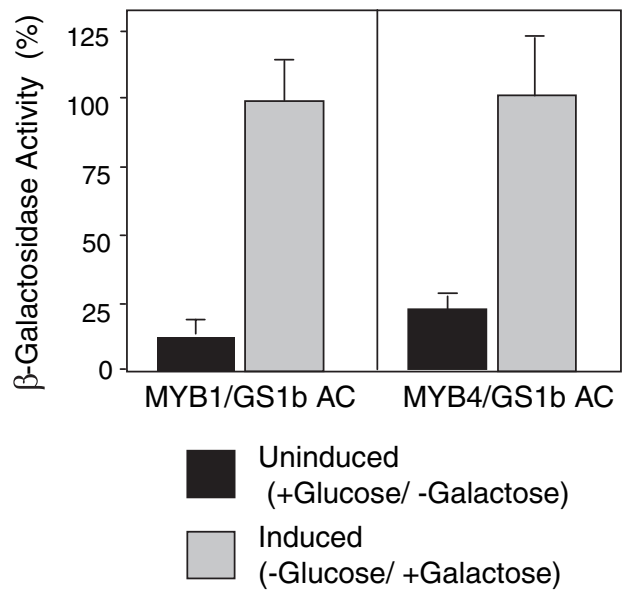

Figure 6. PtMYB1- or PtMYB4-mediated activation of the GS1b AC promoter fragment as determined by transcriptional activation assays in the yeast, Saccharomyces cerevisiae.

(a) Schematic representation of the effector (pYES2trp:MYB) and reporter (pLacZi: GS1b AC) constructs used in this study.

(b) $\beta$-Galactosidase filter-lift assays. Part of a filter containing one representative cotransformant for each MYB is shown. Blue colour indicates transcriptional activation. As a negative control, an experiment was designed to examine the activation using empty reporter vector with one MYB or the other, and the reporter vector with empty effector vector. All showed the same result as the negative control shown.

(c) Quantitative analysis of $\beta$-galactosidase activity in liquid assay with $\rho$-nitrophenyl- $\beta$-D-galactopyranoside (ONPG). $\beta$-Galactosidase units were normalized and expressed as a percentage of maximum data (24.85 $\beta$-galactosidase units). The measurements in liquid assay were made from at least three independent replicates. Error bars represent standard deviations. Activation by the MYB proteins was found to be significantly different from the controls by ANOVA $(P<0.005)$.

Pine MYB proteins are able to activate transcription from the PsGS1b promoter in plant cells

In order to determine whether the pine MYB proteins could alter gene expression derived from the PSGS1b promoter, transient expression assays were undertaken using protoplasts derived from arabidopsis cell suspension cultures or 
(a)
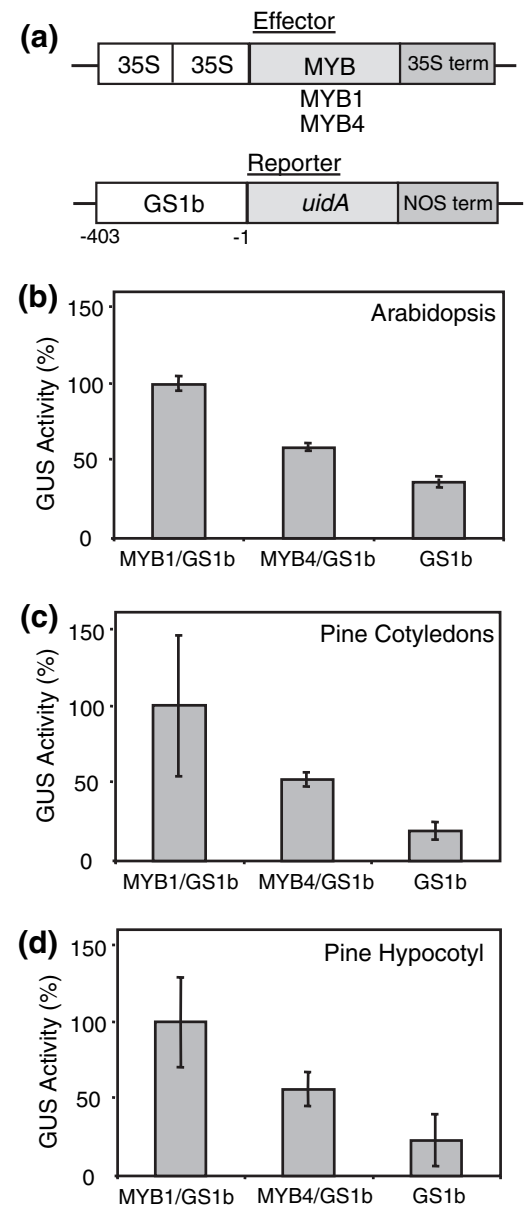

Figure 7. PtMYB1- or PtMYB4-mediated activation of the GS1b AC promoter fragment as determined by transcriptional activation assays in Arabidopsis and pine protoplasts.

(a) Schematic representations of the chimeric effector (pJIT60:MYB) and reporter ( $\mathrm{pBI} 221$ : $G S 1 b A C$ ) constructs used in these transfection experiment. (b) Quantitative analyses of GUS activities in Arabidopsis protoplasts. GUS activity was assayed in Arabidopsis protoplasts from cultured cells and is expressed as a percentage of the maximum level observed (9237.7 pmol MU $\min ^{-1} \mu \mathrm{g}^{-1}$ protein). A promoterless derivative of plasmid $\mathrm{pBI} 221$ was used as a negative control and the background level has been subtracted for the calculation of GUS activity.

(c) Quantitative analyses of GUS activities in protoplasts derived from pine cotyledons. GUS activity was measured and corrected as above and is expressed as percentage of the maximum level observed (22818.25 pmol MU $\min ^{-1} \mu \mathrm{g}^{-1}$ protein).

(d) Quantitative analyses of GUS activities in protoplasts derived from pine hypocotyls. GUS activity was measured and corrected as above and is expressed as percentage of the maximum level observed (11204.75 pmol MU $\min ^{-1} \mu \mathrm{g}^{-1}$ proteins).

In $(b-d)$, the data presented represent the average of three independent transfection experiments. Error bars indicate the standard error. In all cases, activation by the MYB proteins was found to be significantly different from the controls by ANOVA $(P=0.005)$.

from pine seedling tissues. Two different types of constructs were used in these assays. One construct type, the reporter, contained a fusion between the PSGS1b promoter and
uidA, which encodes the reporter $\beta$-glucuronidase (GUS) (Figure 7a). The other construct type, the effector, contained the coding sequences for one of the MYB proteins, which were under the control of a tandem duplication of the cauliflower mosaic virus (CaMV) $35 \mathrm{~S}$ promoter (Figure 7a). In each experiment, the reporter construct was used together with one effector construct, which contained one of the two MYB coding sequences, or, as a control, was the empty vector. Regardless of whether protoplasts were derived from arabidopsis cell cultures (Figure $7 \mathrm{~b}$ ), or from pine cotyledons (Figure 7c) or hypocotyls (Figure 7d), both pine MYB proteins were able to increase PsGS1b promoter-driven GUS expression. In general, PtMYB4 was able to enhance GUS expression by approximately two to threefold above the background levels driven by the PsGS1b promoter alone. In comparison, PtMYB1 was able to enhance GUS expression by approximately four to fivefold above background levels.

\section{Pine MYB proteins are localized to lignifying cells where PsGS1b is expressed}

The data presented above provide circumstantial evidence supporting the hypothesis that MYB proteins may be involved in regulating the PSGS1b promoter in vivo. In order to establish a more direct link between MYB activity and PsGS1b transcription, the pattern of MYB protein accumulation in pine tissues was determined by immunocytochemical localization. Antibodies were raised against the C-terminus of each MYB protein. The C-terminus is highly variable between different MYB proteins (Jin and Martin, 1999; Stracke et al., 2001); consequently, the antibodies raised against each MYB C-terminus should be specific for that protein. When these antibodies were used to detect the presence of each of the MYB proteins in tissues sections prepared from various pine tissues (Figure 8), the pattern of expression reiterated that which had been observed for PsGS1b transcript accumulation using in situ hybridization (Avila et al., 2001).

Antibody detection of PtMYB1 protein revealed that the protein was most abundant in xylem cells in cotyledons, hypocotyl and the root, as well as epidermal cells in the roots (Figure 8). All of these cells are located in zones of lignification, as determined by the co-localization of phloroglucinol- $\mathrm{HCl}$ staining (Figure 8 ). Phloroglucinol- $\mathrm{HCl}$ is a common histochemical stain for the detection of lignins. A similar pattern of expression was observed for PtMYB4, although the amount of immunoreactive material in the cotyledons and roots was less marked than that observed for PtMYB1 (Figure 8). No significant quantity of immunoreactive material was detected when pre-immune serum was used to develop the pine tissue sections. On the basis of presence of immunoreactive material, the abundance of PtMYB1 and PtMYB4 protein appeared to be the greatest in hypocotyl xylem cells (Figure 8), cells that had 


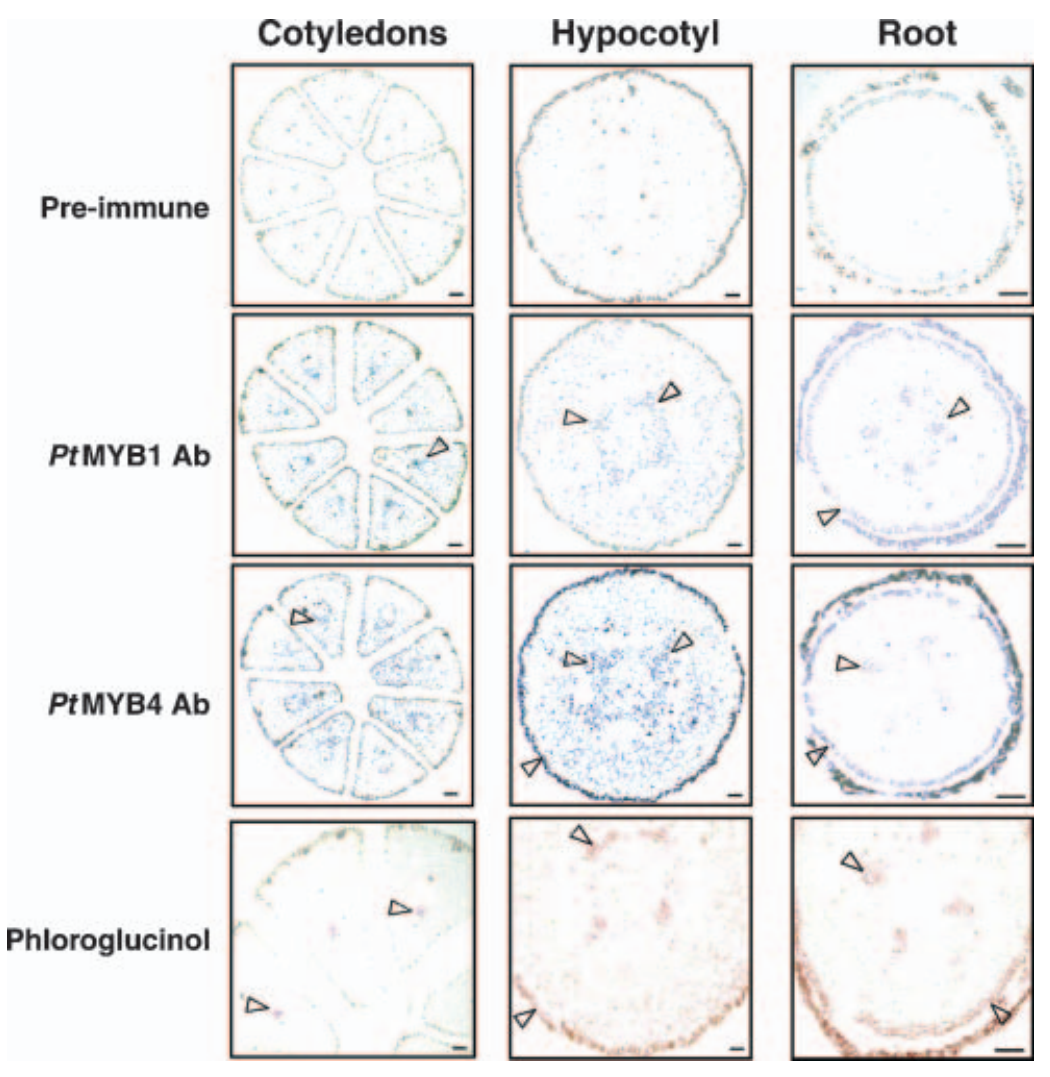

Figure 8. Immunohistochemical localization indicating where proteins that are immunologically identical to the C-terminus of PtMYB1 or the C-terminus of PtMYB4 accumulate in Pinus sylvestris seedlings. Transverse cross-sections through the seedlings were used to determine the localization of proteins that contain epitopes that are recognized by polyclonal antibodies raised against the C-terminus of either PtMYB1 or PtMYB4. Serial sections of various tissues were used for direct comparisons. Arrows indicate the location of immunoreactive material. In all cases the specificity of the signals was established by immunolocalization of control sections with preimmune serum (top row). Lignin accumulation (bottom row) was visualized by staining with phloroglucinol-HCl. Arrows indicate the location of lignified cells. In the upper three rows, the scale bar represents $200 \mu \mathrm{m}$ and in the bottom row it represents $80 \mu \mathrm{m}$.

previously been found to have the greatest accumulation of PsGS1b transcripts (Avila et al., 2001), that is, the MYB proteins co-localized with PSGS1b transcript accumulation.
Thus, these results establish a connection between the localization of MYB proteins and the transcription of the GS1b gene in vivo.

(a)

(b)

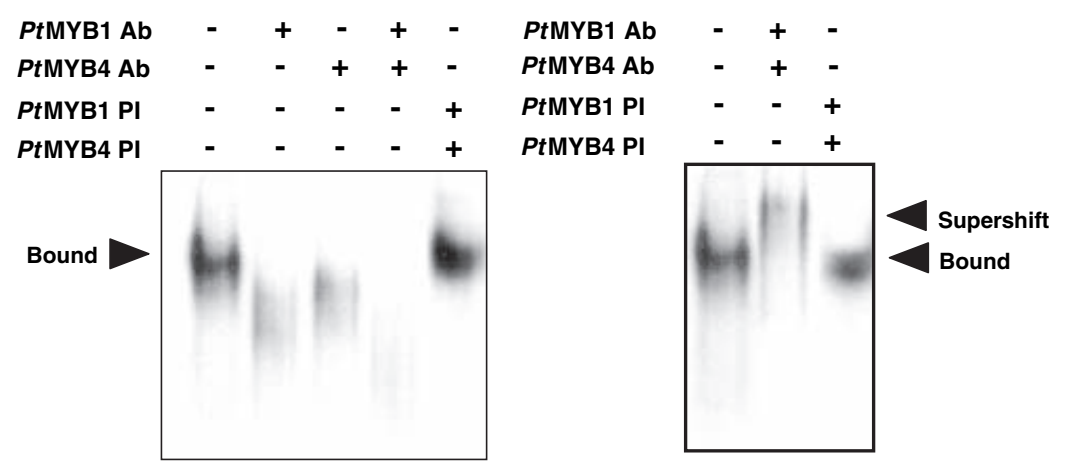

Figure 9. Electrophoretic mobility shift assays (EMSAs) with pine nuclear extracts and polyclonal antibodies (Ab) that are specifically cross-reactive with the C-terminus of PtMYB1 or PtMYB4. The DNA target used in these experiments was PsGS1b AC box 1 and the nuclear extract was from hypocotyls.

(a) Antibody-mediated binding inhibition. Lane 1: A standard EMSA (no antibody incubation). Lane 2: Polyclonal antibodies (0.5 $\mu$ L) raised against the C-terminus of PtMYB1 were pre-incubated with pine nuclear proteins prior to the EMSA as described in Experimental procedures. Lane 3: Polyclonal antibodies raised against the C-terminus of PtMYB4 were pre-incubated with pine nuclear proteins prior to the EMSA. Lane 4: Polyclonal antibodies raised against the C-terminus of PtMYB1 and PtMYB4 were mixed together and pre-incubated with pine nuclear proteins prior to the EMSA. Lane 5: Pre-immune serum (PI) was pre-incubated with pine nuclear proteins prior to the EMSA.

(b) Antibody-mediated reduction of gel mobility (supershift). Lane 1: A standard EMSA (control). Lane 2: Both monospecific antibodies were added to the reactions after the binding reaction between pine nuclear proteins and PsGS1b AC box1. Lane 3: Pre-immune serum (PI) was added to the reaction after the binding reaction between pine nuclear proteins and PSGS1b AC box1. 
Pine MYB proteins are implicated in the ability of pine nuclear extracts to bind to the PsGS1b promoter

The antibodies described above were used to test the hypothesis that the proteins that retarded the migration of PsGS1b promoter in EMSAs corresponded to the MYB proteins. This hypothesis was tested with two different sets of experiments. In the first set of experiments, MYB proteins were immunoprecipitated to remove them from pine nuclear protein extracts prior to conducting the EMSAs, using the PsGS1b AC box 1 as the target. If the antibody for each individual MYB was used to immunoprecipitate that particular protein from a pine nuclear extract prior to the EMSA, there was a marked decrease in the amount of PsGS1b probe that was shifted (Figure 9a). Furthermore, the mobility of the shifted band increased following immunoprecipitation (Figure 9a). If both antibodies were used to immunoprecipitate MYB proteins from pine nuclear extracts prior to conducting the EMSA, there was no detectable band corresponding to the retarded PsGS1b AC box 1 probe (Figure 9a). The pre-immune serum control did not result in a loss of the shifted band, indicating that the anti-MYB antibodies were responsible for immunoprecipitation. These results are consistent with the hypothesis that MYB proteins that contain C-termini that are immunologically identical to PtMYB1 and PtMYB4 are necessary to retard PsGS1b AC box 1 mobility in EMSAs.

In a second set of experiments, the capacity of antibodies to enhance the retardation of the shifted band was tested when they were added at the end of the binding reaction between the PSGS1b AC box 1 probe and pine nuclear extracts. Addition of both antibodies following the binding reaction clearly resulted in a decrease in the mobility of the retarded band, a so-called 'supershift' (Figure 9b). This supershift confirms that proteins that contain C-termini that are immunologically identical to PtMYB1 and PtMYB4 are involved in the retardation of PsGS1b AC box 1 in EMSAs. This result is supported by the fact that addition of pre-immune serum did not induce a supershift, indicating that the anti-MYB antibodies were responsible for the supershift.

\section{Discussion}

The tissue-specific expression of GS isoforms will impact upon a plant's capacity to assimilate and recycle nitrogen. The pine gene that encodes the GS1b isoform is expressed in vascular tissues throughout the plant body, where it is thought to play a role in re-assimilating ammonium liberated from metabolic processes and in the generation of glutamine for $\mathrm{N}$ transport (Avila et al., 2001). The mechanisms that underlie this expression pattern undoubtedly involve the interaction between tissue-specific transcription factors and functional motifs that reside within the GS1b promoter. The current study provides evidence that the promoter of a plant GS gene, in this instance the pine GS1b gene, possesses $A C$ elements and that these regions of the promoter function as sites for the binding of proteins from nuclear extracts in a tissue-specific manner. Furthermore, two different MYB proteins were able to bind to these elements in vitro and to activate transcription from these same elements in yeast and plant cells. These results suggest that one component of the transcriptional machinery that underpins pine GS1b expression in planta may involve the interplay between MYB proteins and cis-acting AC elements residing in the $G S 1 b$ promoter.

\section{Functional significance of AC elements in the PsGS1b promoter}

The organization of the $A C$ element-rich region in the $G S 1 b$ promoter is similar to other promoters that contain AC elements, most notably the bean PAL2 promoter (Hatton et al., 1995). In both cases, the AC-I and AC-II elements are closest to the TATA box; whereas, the AC-III element is much further upstream (Figure 1). The approximately 20 bp spacing between the beginning of the AC-I element and the beginning of the AC-Il element in GS1b AC box 1 is noteworthy in that this spacing would place these sites on the same face of the DNA double helix. This might be important for transcription factor binding. In keeping with this, EMSAs involving the GS1b AC box 1 together with either PtMYB1 or PtMYB4 show a doublet (Figure 3b), suggesting that both putative binding sites can be bound simultaneously. It remains to be determined whether this binding is cooperative.

Analysis of binding to the GS1b promoter fragments by nuclear extracts suggests that they are likely to function as binding sites for putative transcription factors in vivo (Figures 2 and 9). While proteins are clearly able to bind to the $403 \mathrm{bp}$ region of the PsGS1b promoter, the functional significance of the motifs that formed the focus of the studies described herein remains to be determined in planta. Detailed functional dissection of the Gs $1 b$ promoter, equivalent to that which has been carried out for the phenylalanine ammonia-lyase promoter (Hatton et al., 1995), will be necessary to validate the significance of the these motifs in planta.

\section{Significance of differences in MYB activity with the GS1b promoter}

Speculations related to the transcriptional activation capacity of PtMYB1 and PtMYB4, based on the experiments described herein, make two important assumptions. The first assumption is that the MYB proteins act alone, which is by no means certain. While PtMYB1 may function better than PtMYB4 on its own, it may also be that PtMYB4 functions more effectively in concert with other proteins, as has 
been observed for C1, an R2R3-MYB family member from maize (Goff et al., 1992). Proteins present in the plant cells may alter the capacity of either MYB to function as a transcriptional regulator at the GS1b promoter. Some proteins may function to enhance the interaction of the MYB proteins with the target, as is the case with $\mathrm{C} 1$ and its partner B (Goff et al., 1992), whereas other proteins, including other MYB proteins may compete with the PtMYB proteins for the target promoter. Competition between MYB proteins for the same target promoter has been proposed as a 'gearing mechanism' that allows the fine-tuning of gene expression (Moyano et al., 1996). Regardless of what precisely occurs in vivo, it is clear that proteins present in pine nuclear extracts, which contain C-termini that are immunologically identical to PtMYB1 and PtMYB4, are necessary to retard PsGS1b AC box 1 mobility in EMSAs.

The second assumption that has been made in these experiments is that the GS1b promoter is a 'natural' target of the MYB proteins, and that experiments with this promoter provide an accurate reflection of MYB activity. While the data show that PtMYB1 and PtMYB4 were sufficient to enhance GS1b expression in transient assays, they may not be necessary for this activity in vivo. The ectopic overexpression of the MYB proteins may result in target gene responses because of the large quantities of protein produced; therefore, the protoplast overexpression analyses may not accurately reflect the true capacity of the MYB proteins to modulate PsGS1b expression in vivo. Nevertheless, the co-localization of MYB1 and MYB4 protein and GS1b transcripts in the same cells (Avila et al., 2001), and the fact that MYB1 and MYB4 proteins appear necessary for the formation of DNA-protein complexes between the GS1b promoter and pine nuclear extracts (Figure 9), provide compelling support of the hypothesis that GS1b activation by MYB proteins may indeed occur in vivo. Future loss-of-function experiments will be necessary to confirm this hypothesis.

\section{MYB proteins could couple phenylpropanoid metabolism and nitrogen recycling}

As plants must meet all of their nitrogen requirements by uptake from the soil, it is essential that they possess mechanisms to reassimilate inorganic nitrogen that is liberated as part of a variety of metabolic processes in different tissues and nitrogen transport between organs. The existence of such nitrogen recycling is particularly pertinent in the case of phenylpropanoid metabolism, which liberates substantial quantities of nitrogen in the form of ammonium ions.

In order to ensure the efficiency of a nitrogen recycling system that is linked to facets of phenylpropanoid metabolism, such as lignin biosynthesis, it would be ideal if they were spatially and temporally co-regulated. We have shown here that one means by which this could be accomplished is through the involvement of MYB proteins in the transcriptional regulation of these processes. The $A C$ elements in the promoters of genes encoding enzymes involved in phenylpropanoid metabolism, such as $\mathrm{PAL}$, as well as in the promoters of genes encoding nitrogenrecycling enzymes, such as GS, could function as the target of common transcription factors to co-ordinately regulate these pathways. Recent evidence suggests that these two pathways may be regulated at the transcriptional level (Sakurai et al., 2001).

We have shown that two pine MYB proteins, which are normally expressed in differentiating vascular tissue, can activate genes involved in lignin biosynthesis as well as the key gene involved in ammonium reassimilation. This suggests a simple, but important, mechanism that could couple the regulation of these two pathways. We propose that MYB proteins function to co-ordinately regulate phenylpropanoid metabolism and nitrogen cycling. This is an appealing hypothesis, as other branches of phenylpropanoid metabolism, such as flavonoid biosynthesis, are also regulated at the transcriptional level through MYB interactions with $A C$ elements (Borevitz et al., 2000; Sainz et al., 1997). Thus, MYB proteins may function to link a variety of different branches of phenylpropanoid with ammonium reassimilation. Analysis of MYB mutants should allow this hypothesis to be tested in future.

\section{Experimental procedures}

\section{Plant material}

Pinus sylvestris seed germination and growth of the seedlings were as described elsewhere (Cánovas et al., 1991).

\section{Electrophoretic mobility shift assays with pine nuclear extracts}

Nuclear protein extracts were prepared according to published methods (Willmitzer and Wagner, 1981). Either 10 or $5 \mu \mathrm{g}$ of nuclear proteins were used for binding reactions with extracts from cotyledons and hypocotyls, respectively. Each binding mix contained in $20 \mu \mathrm{l}$ of solution $2 \mu \mathrm{l}$ of $10 \mathrm{X}$ binding buffer: $100 \mathrm{~mm}$ Tris $\mathrm{pH} 7.6$, $500 \mathrm{~mm} \mathrm{NaCl}, 10 \mathrm{~mm}$ DTT, $10 \mathrm{~mm}$ EDTA, $50 \%$ glycerol and $0.5 \mu \mathrm{m} \mathrm{ml}^{-1}$ of phenylmethylsulphonylfluoride, leupeptin and antipain, 1.25\% 3-cholamido propyldimethylammonio-1-propane sulphate (CHAPS) and $250 \mathrm{ng}$ of poly $\mathrm{d}(\mathrm{I}+\mathrm{C})$ as an unspecific competitor. This binding solution was pre-incubated for $25 \mathrm{~min}$ at $4^{\circ} \mathrm{C}$ without the DNA radioactive probe to allow the non-specific binding, and then incubated with the radiolabelled probe (30 $000 \mathrm{cpm} /$ reaction) for $30 \mathrm{~min}$. The PsGS1b promoter-derived fragments used as probes are listed in Figure 1. At the end of the incubation period 1/10th of the mix volume of loading buffer was added. The samples were loaded into $5 \%(\mathrm{w} / \mathrm{v})$ polyacrylamide, $2 \%$ glycerol native gel that had been pre-run for $30 \mathrm{~min}$ at $180 \mathrm{~V}$ and electrophoresed for $2-3 \mathrm{~h}$ at $180 \mathrm{~V}$ in $0.5 \mathrm{XTBE}$ buffer at $4^{\circ} \mathrm{C}$. Following electrophoresis, the gel was dried under vacuum on Whatman $3 \mathrm{~mm}$ paper, and exposed O/N to Kodak X-ray film (Amersham Pharmacia Biotech UK Ltd., Little Chalfont, UK) with two intensifying screens. 


\section{PtMYB1 and PtMY4 protein expression and purification}

The full-length cDNAs encoding the PtMYB1 (accession AY356372) and PtMYB4 (accession AY356371) proteins were subcloned into the BamHI /Sall sites of the expression vector pET-30c (Novagen, VWR Ltd., Lutterworth, UK). The regions flanking the insert were sequenced before the plasmid was used for expression. The Escherichia coli strain BL21 (DE3) was used for the expression of the recombinant proteins. Bacterial growth and protein induction were performed as described by the manufacturer (Novagen). Following induction of protein expression in the cells with $0.4 \mathrm{~mm}$ isopropyl- $\beta$-D-thiogalactoside (IPTG), the $\mathrm{N}$-terminus $6 \mathrm{XHis}$-tagged proteins were expressed at $37^{\circ} \mathrm{C}$ for $3 \mathrm{~h}$. Recombinant proteins were purified by affinity chromatography using an Ni-NTA column (Qiagen, Crawley, UK) under denaturing conditions. The purification was verified by SDSPAGE analysis (Laemmli, 1970) and visualization by Coomassie blue staining. The protein was quantified and then protein concentrations were adjusted by dilution so that $0.6 \mu \mathrm{g}$ of the purified proteins was used in the EMSAs described below.

\section{EMSAs with pine MYB proteins}

Purified recombinant PtMYB1 and PtMYB4 proteins were diluted 10 -fold and allowed to denature prior to the binding experiment. Each binding assay contained $0.6 \mu \mathrm{g}$ of the purified MYB protein. EMSA conditions were as described above for nuclear extracts, except that either PtMYB1 or PtMYB4 replaced the nuclear proteins in the assay.

In the proteinase $K$ assay, the proteins were treated with $3 \mu \mathrm{g}$ of proteinase $\mathrm{K}$ for $10 \mathrm{~min}$, at $25^{\circ} \mathrm{C}$ previously to the binding reaction. In specific competition experiments with nuclear proteins, $0-1 \mu \mathrm{g}$ of poly $\mathrm{dl}-\mathrm{dC}$ or poly $\mathrm{dA}-\mathrm{dT}$ were included in the mixes and assayed in standard conditions. In competition experiments, increasing amounts of competitor (50-1000 ng) were included in the assay.

To evaluate the specificity of the DNA sequence in the GS1b promoter fragment involved in the MYB binding complex, competition experiments were performed using the following $A C$ fragments: $\mathrm{ACl}, \mathrm{ACll}$ and $\mathrm{AClll}$ (Figure 4). The appropriate volume of water was replaced with solutions of competitor at the concentrations indicated in Figure 4. The EMSAs were carried out as previously described, except that the radiolabelled probe and the non-radiolabelled competitor were mixed and added together in the second step of the reaction.

The bending assays with MYB proteins were performed as described previously, where salts of the cations $\mathrm{Ba}^{2+}, \mathrm{Mg}^{2+}$ were included in the binding solution (Solano et al., 1995). The added salts were in the chloride form and two different concentrations were used: 50 and $100 \mathrm{~mm}$. As a negative control, $\mathrm{NaCl}$ was added to the binding reaction. The EMSAs were carried out as previously described, except that the time of exposure to the X-ray film was reduced.

\section{Transcriptional activation assays in yeast}

The S. cerevisiae strain W303 was used for all experiments involving yeast. The strain was grown at $30^{\circ} \mathrm{C}$ with shaking. For cultivation prior to transformation, YPD medium containing $1 \%$ yeast extract, $2 \%$ peptone and $2 \%$ glucose was used. Yeast minimal medium (YNB) containing 6.7 g yeast nitrogen base, plus glucose or galactose $(2.0 \% \mathrm{w} / \mathrm{v})$ as the carbon source, and the necessary amino acids or nucleotides, was used in physiological analysis.
Plasmids for the yeast transcriptional activations were prepared using standard techniques and details are available upon request. The yeast expression vector used was pYES2Trp that is a derivate of a pYES2 (Invitrogen) where the nutritional marker URA is replaced with TRP nutritional marker. Full-length cDNAs corresponding to PtMYB1 and PtMYB4 proteins were subcloned into pYES2trp using the $\mathrm{Xhol} / \mathrm{BamHI}$ sites of the polylinker. The yeast reporter vector used was pLacZi (Clontech, BD Biosciences, Cowley, UK). The EcoRI/ Xhol fragment (389 bp) corresponding to the AC-GS1b element (Figure 1) obtained by high-fidelity PCR with Pfu, was cloned into the pLacZi vector. Constructs were verified by sequence analysis.

The yeast co-transformation with pYES2trp and pLacZi constructs was based on a lithium acetate/single-stranded DNA/polyethylene glycol procedure (Agatep et al., 1998). Double-transformed cells were selected on Trp-/Ura-YNB medium and single colonies were isolated for $\beta$-galactosidase assay.

$\beta$-Galactosidase activity was determined by two different assays. One assay was conducted using colony lifts, whereas the other was conducted using liquid cultures. The $\beta$-galactosidase filter-lift assay was performed using X-Gal as substrate. In this assay a sterile Whatman no. 5 filter was placed over the surface of each plate and when the colonies were lifted onto the filter, this was frozen in liquid nitrogen for $10 \mathrm{sec}$ and then was thawed at room temperature to permeabilize the cells. The filters were pre-soaked in Z Buffer/X-Gal solution ( $50 \mathrm{~mm}$ Na Phosphate

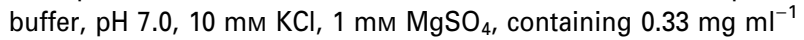
$\mathrm{X}$-Gal) and incubated afterwards at $30^{\circ} \mathrm{C}$ checking by time to time the appearance of blue colonies.

The $\beta$-galactosidase liquid assay was carried out using $\rho$-nitrophenyl- $\beta$-D-galactopyranoside (ONPG) as the substrate. Two millilitres of overnight culture grown in liquid YNB selection medium was used to inoculate $8 \mathrm{ml}$ of the same medium. After 3-5 h growth (OD600 $=0.5-0.8), 1.5 \mathrm{ml}$ aliquots of culture were placed in three $1.5 \mathrm{ml}$ microcentrifuge tubes, and cells were collected by brief centrifugation. Each cell pellet was washed with $1.5 \mathrm{ml}$ of $Z$ buffer ( $50 \mathrm{~mm}$ Na Phosphate buffer, pH 7.0, $10 \mathrm{~mm} \mathrm{KCl}, 1 \mathrm{~mm} \mathrm{MgSO}_{4}$ ), and resuspended in $100 \mu \mathrm{l}$ of $Z$ buffer. Cells were then frozen in liquid nitrogen and thawed at $37^{\circ} \mathrm{C}$ in a water bath three times to break open the yeast cells. Then $0.7 \mathrm{ml}$ of $Z$ buffer containing $0.27 \%(\mathrm{v} / \mathrm{v})$ $\beta$-mercaptoethanol was added to the tube and mixed well, followed by addition of $160 \mu \mathrm{l}$ ONPG in Z buffer $\left(4 \mathrm{mg} \mathrm{ml}^{-1}, \mathrm{pH}\right.$ 7). The tube was incubated at $30^{\circ} \mathrm{C}$ until a yellow colour developed; $0.4 \mathrm{ml}$ of $\mathrm{Na}_{2} \mathrm{CO}_{3}$ was then added to stop the reaction and the reaction time was recorded. The tubes were centrifuged for $10 \mathrm{~min}$ and the absorbance of the supernatant at $420 \mathrm{~nm}$ was measured. The $\beta$-galactosidase activities obtained in the assays were given as a $\beta$-galactosidase unit (1 units of $\beta$-galactosidase is defined as the amount that hydrolyses $1 \mu \mathrm{mol}$ of ONPG to o-nitrophenol and $\mathrm{D}-$ galactose per minute per cell).

\section{Transient expression in pine protoplasts}

In order to construct fusions between the PsGS1b minimal promoter and the GUS reporter gene for transient expression assays, the GS1b promoter (accession AF345985) was amplified between positions -1 and -403 by PCR using appropriate primers. PCR products were inserted into the polylinker of the GUS-encoding plasmid vector pBI221 (Jefferson et al., 1987) in frame with the GUS gene by replacing the full CaMV $35 \mathrm{~S}$ promoter. A promoterless negative control was produced by replacing the full CaMV $35 \mathrm{~S}$ promoter and circularizing after blunt-ending with Klenow enzyme (Roche, Lewes, UK). All DNA constructs were cloned in the pBI221 using general molecular biology methods (Sambrook and Russell, 2001). 
The preparation and electroporation of Maritime pine (Pinus pinaster) protoplasts were based on a published protocol (GómezMaldonado et al., 2001). Protoplast suspensions from cotyledons and hypocotyls were prepared by incubation of $1 \mathrm{~g}$ of fresh cutting tissue in $10 \mathrm{ml}$ of a mixture containing in $0.44 \%(\mathrm{w} / \mathrm{v}) \mathrm{K} 3$ medium: $0.4 \%(\mathrm{w} / \mathrm{v})$ cellulase, $0.4 \%(\mathrm{w} / \mathrm{v})$ macerase (Calbiochem, Merk UK Ltd., Beeston, UK) and $0.4 \%$ sucrose. The incubation was allowed to proceed overnight at $25^{\circ} \mathrm{C}$. Protoplasts were purified by filtration through a $75 \mu \mathrm{m}$ mesh sterile metallic sieve and washed with $0.4 \mathrm{M}$ sucrose and $80 \mathrm{nM} \mathrm{KCl}$. For the electroporation procedure, $50 \mu \mathrm{g}$ of the following DNAs were mixed: $G S 1 b$ minimal promoter:pBI221 and MYB:pJIT60. As a carrier $10 \mu \mathrm{g}$ of sheared salmon sperm DNA was added. A capacitor discharge system was used to deliver $800 \mathrm{~V} \mathrm{~cm}^{-1}$. The protoplasts were left at room temperature for $10 \mathrm{~min}$, then diluted with a volume of $0.5 \mathrm{~m}$ mannitol, $88 \mathrm{~mm}$ sucrose and $0.5 \mathrm{mg} \mathrm{l}^{-1}$ carbenicillin, and were finally cultured in the dark at $24^{\circ} \mathrm{C}$ for $36 \mathrm{~h}$.

\section{Transient expression in Arabidopsis protoplasts}

The Arabidopsis cell suspension used in this experiment was maintained in the following culture medium: 1X MS Salts (Sigma, Poole, UK), $3 \%$ sucrose, $0.5 \mathrm{mg} \mathrm{l}^{-1} \mathrm{NAA}$ and $0.05 \mathrm{mg} \mathrm{I}^{-1}$ Kinetin. The cell suspension was kindly provided by $\mathrm{Dr}$ lan Moore (Department of Plant Sciences, University of Oxford). For protoplast preparation, the culture medium was replaced by the plasmolysis solution $\left(0.4 \mathrm{M}\right.$ mannitol, $3 \%$ sucrose, $\left.8 \mathrm{~mm} \mathrm{CaCl}_{2}\right)$ and incubated for $20 \mathrm{~min}$ at $25^{\circ} \mathrm{C}$. After centrifugation, the pellet containing the protoplasts was resuspended an enzyme solution containing $1 \%$ cellulase and $0.25 \%$ macerozyme (Onozuka R-10, Sigma) for cell wall degradation. The incubation was allowed to proceed for $1 \mathrm{~h} 30 \mathrm{~min}$ at $25^{\circ} \mathrm{C}$ in the dark. Afterwards, the protoplasts were rinsed and resuspended in $5 \mathrm{ml}$ of mannitol/Mg solution [0.4 M mannitol, $0.1 \% \mathrm{MES}\left(\mathrm{pH} 5.7\right.$ ), $15 \mathrm{~mm} \mathrm{MgCl}_{2}$ ]. The PEG-mediated co-transformation was performed with $25 \mu \mathrm{g}$ of each plasmid and $250 \mu \mathrm{g}$ of sheared salmon sperm DNA as a carrier, in a $20 \%$ final concentration of PEG (4000). After an incubation time of $30 \mathrm{~min}$ the transformation mix was diluted gradually to a final volume of $7.6 \mathrm{ml}$ of mannitol/W5 $(0.4 \%$ mannitol diluted $4: 1$ in W5 solution). The protoplasts were allowed to settle for $30 \mathrm{~min}$ at $4^{\circ} \mathrm{C}$, and the supernatant was removed without disturbing the pellet. The protoplasts were resuspended in $2 \mathrm{ml}$ of culture media $\left(0.4 \mathrm{M}\right.$ sucrose, $250 \mathrm{mg} \mathrm{I}^{-1}$ xylose, 1X MS salt media) and incubated at $20^{\circ} \mathrm{C}$ in the dark for $36 \mathrm{~h}$.

\section{Analysis of GUS expression}

Fluorogenic analysis of GUS reporter expression was accomplished according to standard methods (Jefferson et al., 1987) with minor modifications. The reactions were carried out at $37^{\circ} \mathrm{C}$. The resulting fluorescence was measured at 15-min intervals using an FL6000 Bio-TER Fluorescence Reader (BMG, Durham, NC, USA) using methylumbelliferone (MU) as a standard.

\section{Antibody production}

Polyclonal antibodies against the C-terminus of either PtMYB1 or PtMYB4 were raised in New Zealand white rabbits according to published methods (Cantón et al., 1996). Rabbits were immunized by multiple intradermal injections, in the back, of purified protein preparations $(500 \mu \mathrm{g})$ emulsified with Freund's complete adjuvant (Sigma). Forty days later, the animals were boosted with the same amount of protein emulsified with incomplete Freund's adjuvant (Sigma). Ten days later, blood was collected from the ear marginal vein, allowed to clot overnight at $4^{\circ} \mathrm{C}$, and the serum recovered by centrifugation at $4000 \mathrm{~g}$ for $30 \mathrm{~min}$. All experimental procedures were carried out at Centro de Experimentación Animal, Servicios de Investigación, Universidad de Málaga (Spain).

\section{Antibody-mediated EMSA inhibition and antibody-mediated EMSA supershift}

For the EMSA studies with nuclear extracts and polyclonal-antibodies raised against the $\mathrm{C}$-terminus of either PtMYB1 or PtMYB4, two different types of experiments were undertaken:

(i) Antibody-mediated EMSA inhibition, where antigenic nuclear proteins were immunoprecipitated by pre-incubation with monospecific polyclonal antibodies that were raised against PtMYB1 and/or PtMYB4, or with pre-immune serum as a control. Preincubation was for $30 \mathrm{~min}$ at $22^{\circ} \mathrm{C}$ in $20 \mu \mathrm{l}$ of binding buffer containing $250 \mathrm{ng}$ of poly-dldC. EMSAs were continued at $4^{\circ} \mathrm{C}$ for 30 min following the addition of radiolabelled PsGS1b AC box 1 as per the EMSA method detailed above.

(ii) Antibody-mediated supershift, where nuclear proteins were first co-incubated with radiolabelled PsGS1b AC box 1 in $20 \mu \mathrm{l}$ of binding buffer, containing $250 \mathrm{ng}$ of poly-dldC. Binding reactions were continued at $22^{\circ} \mathrm{C}$ for $30 \mathrm{~min}$ following the addition of monospecific polyclonal antibodies that were raised against PtMYB1 and/or PtMYB4, or with pre-immune serum as a control. After incubation, the reactions were analysed as outlined above.

\section{Preparation of plant tissue for microscopy}

Seedlings with a cotyledon length of $5 \mathrm{~mm}$ were harvested and immediately fixed in freshly prepared $4.0 \%(\mathrm{v} / \mathrm{v})$ paraformaldehyde in phosphate buffer saline (PBS) for $4 \mathrm{~h}$ at $4^{\circ} \mathrm{C}$. Plant material was washed in PBS $(3 \times 10 \mathrm{~min})$, dehydrated in a graded ethanol series, and embedded in Fibrowax (BDH Laboratory, VWR Ltd., Lutterworth, UK). The embedded tissues were sectioned to a $10 \mu \mathrm{m}$ thickness, and affixed to poly-L-lysine-coated glass slides.

\section{Immunohistochemical localization}

For light microscopy, the Fibrowax was removed with histoclear (National Diagnostic, Atlanta, GA, USA) and the sections were rehydrated, and then washed in Tris-buffered saline (TBS) $(3 \times 10 \mathrm{~min})$. To inhibit the endogenous phosphatases, the sections where heated for $5 \mathrm{~min}$ in Citrate buffer $10 \mathrm{~mm}$ (pH 6.0). After TBE washing $(3 \times 10 \mathrm{~min})$, sections were blocked for $30 \mathrm{~min}$ in TBS containing $5 \%$ bovine serum albumin (BSA). To immunolocalize PtMYB1 or PtMYB4, the sections were incubated for $1 \mathrm{~h}$ with monospecific antibodies and then for $2 \mathrm{~h}$ with alkaline phosphataseconjugated secondary antibodies (Sigma). Control slides were treated with pre-immune serum. Alkaline phosphatase was detected colorimetrically, by incubation in darkness in a mixture of TBS $\mathrm{pH}$ 9.0), $50 \mathrm{~mm} \mathrm{MgCl}_{2}$ containing NBT/BCIP as substrate (Roche). The reaction was stopped by washing with water. For observation of lignin accumulation, deparaffinized and rehydrated tissue sections were stained for $2 \mathrm{~min}$ in $2.5 \%$ (w/v) phloroglucinol-HCl (Sigma), and then rinsed with water. Slides were dehydrated and mounted with Entellan (Merck). An Eclipse E800 microscope (Nikon, Kingston upon Thames, UK) was used for sample visualization and photography. 


\section{Protein determination}

The concentration of protein in all protein-based assays was determined by the method of Bradford (1976) using BSA as standard.

\section{Acknowledgements}

We are grateful to Dr lan Moore for the provision of arabidopsis cell cultures and Dr Stephen Rutherford for guidance in making arabidopsis protoplasts. We are very grateful to members of the Cánovas and Campbell laboratories for their kind assistance in various aspects of this work. This work has been supported by a studentship and travel funds from the Ministerio de Ciencia y Tecnología de España to J.G.-M., grants from the Ministerio de Ciencia y Tecnología de España (PB98-1396 and BCM2003-4772) to F.M.C., grants from the UK Biotechnology and Biological Sciences Research Council (BBSRC) to M.M.C., and travel funds from the Department of Plant Sciences, University of Oxford and the Universidad de Málaga to M.M.C.

\section{References}

Agatep, R., Kirkpatrick, R.D., Parchaliuk, D.L., Woods, R.A. and Gietz, R.D. (1998) Transformation of Saccharomyces cerevisiae by the lithium acetate/single-stranded carrier DNA/polyethylene glycol protocol. Technical Tips Online, 1, P01525.

Anterola, A.M., Jeon, J.-H., Davin, L.B. and Lewis, N.G. (2002) Transcriptional control of monolignol biosynthesis in Pinus taeda: factors affecting monolignol ratios and carbon allocation in phenylpropanoid metabolism. J. Biol. Chem. 277, 1827218280.

Avila, C., García-Gutiérrez, A., Crespillo, R. and Cánovas, F.M. (1998) Effects of phosphinotricin treatment on glutamine synthetase isoforms in Scots pine seedlings. Plant Physiol. Biochem. 36, 857863.

Avila, C., Suárez, M.F., Gómez-Maldonado, J. and Cánovas, F.M. (2001) Spatial and temporal expression of two cytosolic glutamine synthetase genes in Scots pine: functional implications on nitrogen metabolism during early stages of conifer development. Plant J. 25, 93-102.

Avila Sáez, C., Munoz-Chapuli, R., Plomion, C., Frigerio, J. and Cánovas, F.M. (2000) Two genes encoding distinct cytosolic glutamine synthetases are closely linked in the pine genome. FEBS Lett. 477, 237-243.

Bell-Lelong, D.A., Cusumano, J.C., Meyer, K. and Chapple, C. (1997) Cinnamate-4-hydroxylase expression in Arabidopsis. Regulation in response to development and the environment. Plant Physiol. 113, 729-738.

Bielawski, W. (1994) Purification and partial characterization of glutamine synthetase isoforms from Triticale seedlings. Acta Biochim. Pol. 41, 397-404.

Borevitz, J.O., Xia, Y., Blount, J., Dixon, R.A. and Lamb, C. (2000) Activation tagging identifies a conserved MYB regulator of phenylpropanoid biosynthesis. Plant Cell, 12, 2383-2394.

Bradford, M.M. (1976) A rapid and sensitive method for the quantitation of microgram quantities of protein utilizing the principle of protein-dye binding. Anal. Biochem. 72, 248-254.

Campbell, M.M. and Sederoff, R. (1996) Variation in lignin content and composition. Plant Physiol. 110, 3-13.

Cánovas, F.M., Cantón, F.R., Gallardo, F., García-Gutiérrez, A. and de Vicente, A. (1991) Accumulation of glutamine synthetase during early development of maritime pine (Pinus pinaster) seedlings. Planta, 185, 372-378.
Cánovas, F.M., Canton, F.R., Garcia-Gutierrez, A., Gallardo, F. and Crespillo, R. (1998) Molecular physiology of glutamine and glutamate biosynthesis in developing seedlings of conifers. Physiol. Plant. 103, 287-294.

Cantón, F.R., García-Gutiérrez, A., Crespillo, R. and Cánovas, F.M. (1996) High-level expression of Pinus sylvestris glutamine synthetase in Escherichia coli. Production of polyclonal antibodies against the recombinant protein and expression studies in pine seedlings. FEBS Lett. 393, 205-210.

Capellades, M., Torres, M.A., Bastisch, I., Stiefel, V., Vignols, F., Bruce, W.B., Peterson, D., Puigdomenech, P. and Rigau, J. (1996) The maize caffeic acid O-methyltransferase gene promoter is active in transgenic tobacco and maize plant tissues. Plant Mol. Biol. 31, 307-322.

Chen, Q. and Silflow, C.D. (1996) Isolation and characterization of glutamine synthetase genes in Chlamydomonas reinhardtii. Plant Physiol. 112, 987-996.

Cren, M. and Hirel, B. (1999) Glutamine synthetase in higher plants: regulation of gene and protein expression from the organ to the cell. Plant Cell Physiol. 40, 1187-1193.

Edwards, J., Walker, E. and Coruzzi, G. (1990) Cell-specific expression in transgenic plants reveals nonoverlapping roles for chloroplast and cytosolic glutamine synthetase. PNAS, 87, 34593463.

Goff, S.A., Cone, K.C. and Chandler, V.L. (1992) Functional analysis of the transcriptional activator encoded by the maize $B$ gene: evidence for a direct functional interaction between two classes of regulatory proteins. Genes Dev. 6, 864-875.

Gómez-Maldonado, J., Crespillo, R., Avila, C. and Cánovas, F.M. (2001) Efficient preparation of maritime pine (Pinus pinaster) protoplasts suitable for transgene expression analysis. Plant Mol. Bio. Rep. 19, 361-366.

Gómez-Maldonado, J., Cánovas, F.M. and Avila, C. (2004) Molecular analysis of the $5^{\prime}$ upstream region of a gibberellin-inducible cytosolic glutamine synthetase gene (GS1b) expressed in the pine vascular tissue. Planta, 218, 1036-1045.

Hatton, D., Sablowski, R., Yung, M.H., Smith, C., Schuch, W. and Bevan, M. (1995) Two classes of cis sequences contribute to tissue-specific expression of a PAL2 promoter in transgenic tobacco. Plant J. 7, 859-876.

Hauffe, K.D., Lee, S.P., Subramaniam, R. and Douglas, C.J. (1993) Combinatorial interactions between positive and negative cisacting elements control spatial patterns of $4 \mathrm{CL}-1$ expression in transgenic tobacco. Plant J. 4, 235-253.

Hawkins, S., Boudet, A. and Grima-Pettenati, J. (2003) Characterisation of caffeic acid O-methyltransferase and cinnamyl alcohol dehydrogenase gene expression patterns by in situ hybridisation in Eucalyptus gunnii Hook. plantlets. Plant Sci. 164, 165-173.

van Heerden, P.S., Towers, G.H. and Lewis, N.G. (1996) Nitrogen metabolism in lignifying Pinus taeda cell cultures. J. Biol. Chem. 271, 12350-12355.

Hirel, B., McNally, S.F., Gadal, P., Sumar, N. and Stewart, G.R. (1984) Cytosolic glutamine synthetase in higher plants. A comparative immunological study. Eur. J. Biochem. 138, 63-66.

Jefferson, R.A., Kavanagh, T.A. and Bevan, M.W. (1987) GUS fusions: beta-glucuronidase as a sensitive and versatile gene fusion marker in higher plants. EMBO J. 6, 3901-3907.

Jin, H. and Martin, C. (1999) Multifunctionality and diversity within the plant MYB-gene family. Plant Mol. Biol. 41, 577-585.

Lacombe, E., Van Doorsselaere, J., Boerjan, W., Boudet, A.M. and Grima-Pettenati, J. (2000) Characterization of cis-elements required for vascular expression of the cinnamoyl CoA reductase gene and for protein-DNA complex formation. Plant J. 23, 663676. 
Laemmli, U.K. (1970) Cleavage of structural proteins during the assembly of the head of bacteriophage T4. Nature, 227, 680-685.

Leyva, A., Liang, X., Pintor-Toro, J.A., Dixon, R.A. and Lamb, C.J. (1992) cis-element combinations determine phenylalanine ammonia-lyase gene tissue-specific expression patterns. Plant Cell, 4, 263-271.

McNally, S.F., Hirel, B., Gadal, P., Mann, A.F. and Stewart, G.R. (1983) Glutamine synthetases of higher plants - evidence for a specific isoform content related to their possible physiological role and their compartmentation within the leaf. Plant Physiol. 72, 22-25.

Moyano, E., Martinez-Garcia, J.F. and Martin, C. (1996) Apparent redundancy in myb gene function provides gearing for the control of flavonoid biosynthesis in antirrhinum flowers. Plant Cell, $\mathbf{8}$, 1519-1532.

Nair, R.B., Xia, Q., Kartha, C.J., Kurylo, E., Hirji, R.N., Datla, R. and Selvaraj, G. (2002) Arabidopsis CYP98A3 mediating aromatic 3-hydroxylation. Developmental regulation of the gene, and expression in yeast. Plant Physiol. 130, 210-220.

Patzlaff, A., Newman, L.J., Dubos, C., Whetten, R.W., Smith, C., McInnis, S., Bevan, M.W., Sederoff, R.R. and Campbell, M.M. (2003a) Characterisation of PtMYB1, an R2R3-MYB from pine xylem. Plant Mol. Biol. 53, 597-608.

Patzlaff, A., McInnis, S., Courtenay, A. et al. (2003b) Characterisation of a pine MYB that regulates lignification. Plant J. 36, 743-754.

Raes, J., Rohde, A., Christensen, J.H., Van de Peer, Y. and Boerjan, W. (2003) Genome-wide characterization of the lignification toolbox in Arabidopsis. Plant Physiol. 133, 1051-1071.

Razal, R.A., Ellis, S., Santokh, S., Lewis, N.G. and Towers, G.H.N. (1996) Nitrogen recycling in phenylpropanoid metabolism. Phytochemistry, 41, 31-35.

Sainz, M.B., Grotewold, E. and Chandler, V.L. (1997) Evidence for direct activation of an anthocyanin promoter by the maize $\mathrm{C} 1$ protein and comparison of DNA binding by related Myb domain proteins. Plant Cell, 9, 611-625.
Sakurai, N., Katayama, Y. and Yamaya, T. (2001) Overlapping expression of cytosolic glutamine synthetase and phenylalanine ammonia-lyase in immature leaf blades of rice. Physiol. Plant. 113, 400-408.

Sambrook, J. and Russell, D.W. (2001) Molecular Cloning: $A$ Laboratory Manual. Cold Spring Harbor, New York: Cold Spring Harbor Laboratory Press.

Singh, S., Lewis, N.G. and Towers, G.H. (1998) Nitrogen recycling during phenylpropanoid metabolism in sweet potato tubers. J. Plant Physiol. 153, 316-323.

Solano, R., Nieto, C. and Paz-Ares, J. (1995) MYB.Ph3 transcription factor from Petunia hybrida induces similar DNA-bending/distortions on its two types of binding site. Plant J. 8, 673-682.

Stracke, R., Werber, M. and Weisshaar, B. (2001) The R2R3-MYB gene family in Arabidopsis thaliana. Curr. Opin. Plant Biol. 4, 447456.

Suárez, M.F., Avila, C., Gallardo, F., Cantón, F.R., García-Gutiérrez, A., Claros, M.G. and Cánovas, F.M. (2002) Molecular and enzymatic analysis of ammonium assimilation in woody plants. J. Exp. Bot. 53, 891-904.

Tingey, S.V., Tsai, F.Y., Edwards, J.W., Walker, E.L. and Coruzzi, G.M. (1988) Chloroplast and cytosolic glutamine synthetase are encoded by homologous nuclear genes which are differentially expressed in vivo. J. Biol. Chem. 263, 9651-9657.

Tobin, A.K. and Yamaya, T. (2001) Cellular compartmentation of ammonium assimilation in rice and barley. J. Exp. Bot. 52, 591604.

de la Torre, F., García-Gutiérrez, A., Crespillo, R., Cantón, F.R., Avila, C. and Cánovas, F.M. (2002) Functional expression of two pine glutamine synthetase genes in bacteria reveals that they encode cytosolic holoenzymes with different molecular and catalytic properties. Plant Cell Physiol. 43, 802-809.

Willmitzer, L. and Wagner, K.G. (1981) The isolation of nuclei from tissue-cultured plant cells. Exp. Cell Res. 135, 69-77. 